\title{
Thrombosis of the Abdominal Veins in Childhood
}

\author{
Riten Kumar ${ }^{1,2}$ and Bryce A. Kerlin ${ }^{1,2,3 *}$ \\ ${ }^{1}$ Department of Pediatrics, The Ohio State University College of Medicine, Columbus, $\mathrm{OH}$, United States, ${ }^{2}$ Division of \\ Pediatric Hematology/Oncology/BMT, Nationwide Children's Hospital, Columbus, OH, United States, ${ }^{3}$ Center for Clinical \\ and Translational Research, The Research Institute at Nationwide Children's Hospital, Columbus, OH, United States
}

Abdominal venous thrombosis is a rare form of venous thromboembolic disease in children. While mortality rates are low, a significant proportion of affected children may suffer long-term morbidity. Additionally, given the infrequency of these thrombi, there is lack of stringent research data and evidence-based treatment guidelines. Nonetheless, pediatric hematologists and other subspecialists are likely to encounter these problems in practice. This review is therefore intended to provide a useful guide on the clinical diagnosis and management of children with these rare forms of venous thromboembolic disease. Herein, we will thus appraise the current knowledge regarding major forms of abdominal venous thrombosis in children. The discussion will focus on the epidemiology, presentation, diagnosis, management, and outcomes of (1) inferior vena cava, (2) portal, (3) mesenteric, (4) hepatic, and (5) renal vein thrombosis.

Keywords: thrombosis, inferior vena cava, portal vein, mesenteric vein, Budd-Chiari, renal vein

\section{INTRODUCTION}

Though rare in children, abdominal venous thromboembolism (VTE) may result in substantial morbidity. In our recent epidemiologic study, there were 4,538 pediatric VTE discharges in 1 year (1). Of these, $17 \%$ were abdominal VTE, $44 \%$ involved the inferior vena cava (IVC), $36 \%$ portal veins, $11 \%$ hepatic veins, and $10 \%$ were renal vein thrombi. In a prospective study of 466 childhood VTE, $12 \%$ were abdominal; $46 \%$ of which were in the IVC (2). Thus, $12-17 \%$ of childhood VTE is intraabdominal with IVC thrombosis predominating. High-quality data are limited, thus the following recommendations are based on available literature, expert consensus, and personal experience. The use of anticoagulants in pediatric VTE is comprehensively reviewed in another manuscript in this collection (3).

\section{IVC THROMBOSIS}

The majority of IVC thrombi result from extension of ilio-femoral deep vein thrombi (DVT) which, in turn, are a common complication of femoral vein catheterization (4-7). Neonates are prone to catheter-related IVC thrombosis, due to the common utilization of lower extremity and umbilical venous catheters (UVCs). In a Dutch study, $66 \%$ of 44 catheter-related thrombi in neonates involved the IVC or right atrium whereas the IVC was not involved in non-catheter-related neonatal VTE (5). In a Canadian registry of catheter-related VTE in children of all ages, IVC involvement was appreciated in $10 \%$ of the cohort (6). In the PROTEKT trial, $29 \%$ of catheter-related VTE were found in the lower extremity venous system, and one-third of these extended into either the superior or inferior vena cava (7). Thus, it is important to identify the proximal extension of all catheter-related VTE to define the anatomic scope of involvement. 
Congenital IVC agenesis/atresia, which has an estimated prevalence of $\sim 0.6 \%$, may present with calcified IVC thrombosis during infancy (8-11). This is most commonly an incidental imaging finding in an asymptomatic infant. However, IVC anomalies occasionally present during adolescence as what initially appears to be unprovoked, proximal lower extremity DVT (12-14). Two recent studies which included adolescents, found that $11-13 \%$ of IVC thromboses had evidence of congenital IVC anomaly, whereas none of the control group (cases of lower extremity DVT without IVC involvement) had anomalies (15, 16). In cases of delayed presentation, it is thought that collateral venous drainage is accomplished via deep, median, portal, or superficial abdominal veins (17). It is reasonable to hypothesize an anatomic thrombophilia due to increased vascular resistance in these smaller veins, which predisposes to lower extremity DVT. Therefore, it is appropriate to maintain a high index of suspicion for IVC anomalies in children with lower extremity DVT who have no apparent thrombotic predisposition. IVC thrombosis has also been reported following physical abuse and major abdominal surgery in children (18-21).

Doppler ultrasonography, the imaging modality of choice for extremity thrombosis, may miss isolated pathology of the IVC; thus computed tomography (CT) and magnetic resonance scans are preferable (22). Anticoagulant therapy for a period of 3-6 months is appropriate for provoked and unprovoked initial episodes (23). Some authors suggest an initial course of 12 months given concerns for significant post-thrombotic syndrome (PTS) with persistent IVC thrombosis $(24,25)$. Additionally, some experts advocate thrombolytic therapy as initial treatment $(26,27)$. It is thought that such an aggressive intervention may decrease the risk for PTS, pulmonary embolism, or acute renal failure (in the setting of suprarenal IVC thrombosis). However, this strategy is based upon expert consensus and thus awaits clinical trial data. Successful IVC stenting followed by aspirin prophylaxis has been reported in children with congenital heart disease and subacute/chronic thrombotic IVC obstruction (28). With regard to IVC agenesis/atresia, IVC reconstruction utilizing polytetrafluoroethylene grafts has demonstrated $83 \%$ patency with stable or improved PTS scores at 41 months (29).

Long-term IVC thrombosis outcome has been studied in 39 children who were followed for a maximum of 18 years (24). Six patients (15\%) died within 3 months of diagnosis. Twenty-one (53\%) presented with extensive thrombosis (defined as involving $\geq 2$ IVC segments or extending into the iliac veins; Figure 1). Complete reconstitution of IVC flow was observed in only four (19\%) children; three of whom had undergone intervention [thrombolysis (1); surgical (2)]. Persistent caval and/or iliac obstruction was observed in the remaining 17 (81\%) patients (6 of whom had been treated with thrombolysis). The remaining $12(30 \%)$ had complete resolution of limited IVC thrombosis on follow-up. PTS was frequent (30\%) in those with persistent IVC pathology (24).

\section{PORTAL VEIN THROMBOSIS (PVT)}

Portal vein thrombosis refers to partial or complete occlusion of the portal venous system (Figure 1). Thrombus may be

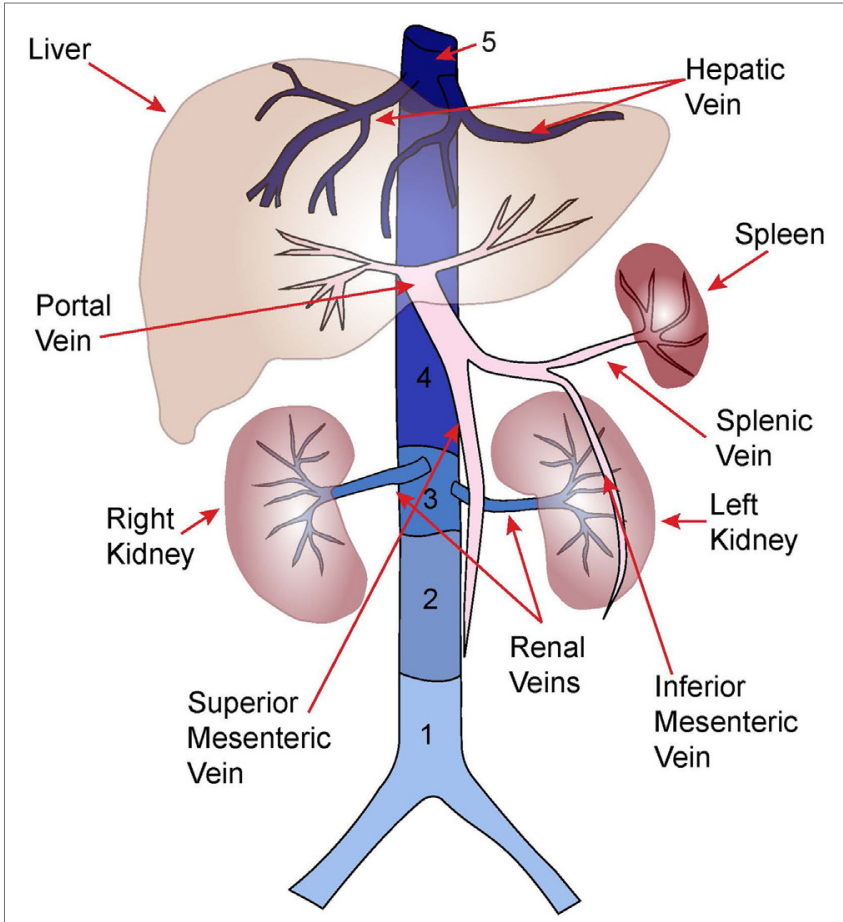

FIGURE 1 | Anatomy of major abdominal veins. Inferior vena cava segments adapted from Ref. (8).

restricted to the portal veins or may extend into the splenic and/or superior mesenteric veins. PVT often occurs during the neonatal period with an estimated incidence of 1.3/100,000 live births, and 36/1,000 NICU admissions $(9,30)$. However, neonatal PVT is often asymptomatic and only identified in the subset of patients who develop symptomatic portal hypertension [e.g., gastrointestinal (GI) bleeding, splenomegaly] several years after the initial thrombotic event $(31,32)$. Thus, the true incidence is likely higher.

In neonates, UVC placement is the most common cause for PVT. In a retrospective Canadian study of 133 neonates with PVT, 73\% were UVC-associated (30). In contrast, incidence of UVC-associated PVT in prospective studies ranges from 0 to $43 \%$ (33-37). This variation may be explained by study design differences, diagnostic criteria, and timing of imaging. Other risk factors for neonatal PVT include prolonged catheterization, position of catheter tip, transfusion through the UVC, and sepsis $(30,35,36)$. In older children and adults, etiologies of PVT include pancreatitis, cirrhosis, liver transplant, splenectomy, and sickle cell disease (32). Notably, $\sim 50 \%$ of childhood PVT has no identifiable etiology $(31,32)$.

Because neonatal PVT is often asymptomatic, the diagnosis is often an incidental finding of imaging performed for other indications. In the Canadian study, the most common indications for imaging were thrombocytopenia (20\%), abdominal distension (17\%), elevated liver enzymes (7\%), and hepatosplenomegaly (4\%) (30). Many cases of neonatal PVT are diagnosed later in childhood secondary to symptoms of portal hypertension. It is estimated that 5-20\% of childhood portal hypertension cases are 
secondary to PVT (38). In a retrospective study of 108 children with chronic PVT, 52\% presented with splenomegaly and $46 \%$ with GI hemorrhage (31). Eventually, 79\% of the children developed GI bleeding.

Doppler ultrasonography is the most common imaging modality used to diagnose PVT. Acute PVT may be graded ultrasonographically: (a) Grade I: non-occlusive single-branch PVT with normal liver parenchyma, (b) Grade II: occlusive single-branch PVT with normal liver parenchyma, and (c) Grade III: occlusive PVT involving two-branches or occlusive singlebranch PVT with liver parenchymal changes (30). An association between Grade III PVT and poor outcome (portal hypertension or liver lobe atrophy) was noted in the original study (30), though a follow-up study failed to confirm this finding (39). Pancreaticoduodenal and peribilliary collaterals may develop around the obstructed veins and are known as "cavernous transformation." This process begins within 5 weeks after the thrombotic event but may take months-to-years to become apparent ultrasonographically (40). Procoagulant defects have been reported in a substantial proportion of patients with PVT (Table 1) (9, 39, 41-43). In adolescents with unprovoked PVT, we suggest testing for paroxysmal nocturnal hemoglobinuria and Janus tyrosinekinase 2 (JAK2) mutations $(44,45)$.
The utility of anticoagulation for PVT remains unclear since a significant proportion resolve spontaneously. In the Canadian study, $77 \%$ of non-occlusive PVT resolved completely or partially whereas only $48 \%$ of occlusive PVT resolved. Anticoagulation was administered to $44 \%$ of the cohort, but did not appear to influence outcome (30). Similarly, a $70 \%$ resolution rate was appreciated for non-occlusive PVT vs. only $31 \%$ for occlusive PVT in another study (35). Given the ambiguity surrounding the role of anticoagulation and high rate of spontaneous resolution, there are no consensus guidelines for PVT management (23). Thus, anticoagulation should be considered on a caseby-case basis. In neonates with acute, occlusive PVT and no contraindications, 6-12 weeks of anticoagulation is reasonable. Conversely, in patients who are at risk for bleeding or for nonocclusive PVT, supportive care, and serial ultrasonography monitoring may be appropriate. An expert panel recommends annual screening for evolving portal hypertension for $\geq 5$ years post-diagnosis (38).

Anticoagulation is not indicated for cavernous transformation due to the high rate of variceal bleeding. These children should be referred to gastroenterology for measures to prevent variceal bleeding, which may include: (a) $\beta$-adrenergic antagonists, (b) endoscopic variceal band ligation, or (c) endoscopic sclerotherapy

TABLE 1 | Studies investigating the association between thrombophilia and abdominal vein thrombosis.

\begin{tabular}{|c|c|c|c|c|c|}
\hline Reference & $\begin{array}{c}\text { Year of } \\
\text { publication }\end{array}$ & $\begin{array}{l}\text { Type of } \\
\text { study }\end{array}$ & $\begin{array}{l}\text { Subjects } \\
\text { tested }\end{array}$ & Thrombophilia identified (\%) & $\begin{array}{l}\text { OR }(95 \% \\
\quad \mathrm{Cl})\end{array}$ \\
\hline \multicolumn{6}{|l|}{ Portal vein thrombosis } \\
\hline Heller et al. (9) & 2000 & $\begin{array}{l}\text { Case- } \\
\text { control }\end{array}$ & 24 & FV Leiden: 4 (17\%), PC deficiency: 1 (4\%), AT deficiency: 1 (4\%) & $\begin{array}{c}5.47 \\
(1.7-17.6)\end{array}$ \\
\hline El-Karaksy et al. (41) & 2003 & $\begin{array}{l}\text { Case- } \\
\text { control }\end{array}$ & 40 & $\begin{array}{l}\text { FV Leiden: } 12 \text { (30\%), PC deficiency: } 11 \text { (28\%), PG20210: } 6 \text { (15\%), } \\
\text { AT deficiency: } 1 \text { (3\%) }\end{array}$ & $\begin{array}{l}6 \text { (for FV } \\
\text { Leiden only) }\end{array}$ \\
\hline Morag et al. (39) & 2011 & Cohort & 25 & PS deficiency: 2 (8\%), FV Leiden: 2 (8\%), AT deficiency: 1 (4\%) & NA \\
\hline Pietrobattista et al. (43) & 2010 & $\begin{array}{l}\text { Case- } \\
\text { control }\end{array}$ & 31 & PC deficiency: 4 (13\%), PS deficiency: 4 (13\%), PG20210: 3 (10\%), FV Leiden: 2 (6\%) & $\begin{array}{c}11.91 \\
(1.4-100.7)\end{array}$ \\
\hline Ferri et al. $(32,42)$ & 2012 & Cohort & 32 & APLA: 2 (6\%), FV Leiden + PG20210:1 (3\%) & NA \\
\hline \multicolumn{6}{|c|}{ Neonatal renal vein thrombosis } \\
\hline Heller et al. (9) & 2000 & $\begin{array}{l}\text { Case- } \\
\text { control }\end{array}$ & 31 & FV Leiden: 9 (29\%), PC deficiency: 2 (7\%), AT deficiency: 1 (3\%) & $\begin{array}{c}10.9 \\
(3.9-31.1)\end{array}$ \\
\hline Kuhle et al. (46) & 2004 & $\begin{array}{l}\text { Cross- } \\
\text { sectional }\end{array}$ & 21 & FV Leiden: 8 (38\%), PG20210 (homozygous): 1 (5\%) & NA \\
\hline Kosch et al. (47) & 2004 & $\begin{array}{l}\text { Case- } \\
\text { control }\end{array}$ & 59 & FV Leiden: 22 (38\%), PG20210: 5 (9\%), PC deficiency: 3 (5\%), AT deficiency: 3 (5\%) & $\begin{array}{c}15.6 \\
(7.2-34.2)\end{array}$ \\
\hline Marks et al. (48) & 2005 & Cohort & 28 & $\begin{array}{l}\text { PC/PS deficiency: } 5 \text { (18\%), FV Leiden: } 5 \text { (18\%), PG20210: } 1 \text { (4\%), } \\
\text { AT deficiency: } 1 \text { (4\%) }\end{array}$ & NA \\
\hline Winyard et al. (49) & 2006 & Cohort & 18 & FV Leiden: 4 (22\%), PC + PS deficiency: 1 (6\%) & NA \\
\hline \multicolumn{6}{|c|}{ Hepatic vein thrombosis } \\
\hline Heller et al. (9) & 2000 & $\begin{array}{l}\text { Case- } \\
\text { control }\end{array}$ & 10 & FV Leiden: 1 (10\%) & $\begin{array}{c}3.3 \\
(0.6-18.7)\end{array}$ \\
\hline Nagral et al. (50) & 2010 & Cohort & 16 & PC deficiency: 2 (13\%)a , AT deficiency: 1 (6\%), APLA: 1 (6\%) & NA \\
\hline Kathuria et al. (51) & 2014 & Cohort & 12 & $\begin{array}{l}\text { PC deficiency: } 6(50 \%)^{\mathrm{a}} \text {, PS deficiency: } 3(25 \%)^{\mathrm{a}} \text {, APLA syndrome: } 3(25 \%)^{\mathrm{b}} \text {, } \\
\text { hyperhomocysteinemia: } 2(17 \%) \text {, AT deficiency: } 1(8 \%)^{\mathrm{a}}\end{array}$ & $\mathrm{NA}$ \\
\hline
\end{tabular}

PC, protein C; PS, protein S; AT, antithrombin; APLA, anti-phospholipid antibody syndrome; FV Leiden, Factor V Leiden mutation (FV R506Q); PG20210, prothrombin gene mutation (Fll G20210A); NA, not applicable.

aLow PC, PS, and AT levels may be acquired in the setting of advanced liver disease.

bunclear if abnormal labs were repeated 12 weeks apart to confirm APLA syndrome. Note: pediatric data regarding the association of thrombophilia with IVC thrombosis/atresia and mesenteric vein thrombosis not available. 
(52). Creation of a vascular shunt between the mesenteric vein and left portal vein (Rex shunt) can reduce portal hypertension and restore portal venous flow through the liver (52). Rex shunts are associated with improved growth and cognitive performance, decreased hypersplenism, and prevention of hepatopulmonary syndrome (53-55). Rex shunts are thus recommended for both primary and secondary prophylaxis of variceal bleeding in children with portal hypertension (56).

\section{MESENTERIC VEIN THROMBOSIS (MVT)}

Mesenteric vein thrombosis (Figure 1) is exceedingly rare in children with literature limited to case reports and series (57-60). Pancreatitis, surgery, trauma, and oral contraceptives have been associated with pediatric MVT. Early detection and aggressive management are imperative to prevent thrombus progression, bowel infarction, and death (58).

Symptoms of acute MVT are dependent on thrombus size and location, as well as depth of bowel-wall ischemia and include abdominal pain, tenderness, nausea, vomiting, diarrhea, and hematochezia (61). Lactic acidosis may be seen late in the disease course, after bowel infarction has ensued. Early diagnosis is dependent on appropriate imaging studies in symptomatic patients. Plain films are typically non-specific but may include dilated, thickened bowel loops, and multiple air-fluid levels suggestive of ileus. Pneumatosis intestinalis, portal vein gas, and free peritoneal air may be seen later and are characteristic of bowel infarction (61). Doppler ultrasonography may be attempted, but it is often insufficient to adequately evaluate the mesenteric vein. Thus, CT with contrast is preferred and able to confirm the diagnosis in $~ 90 \%$ of cases (62). CT may simultaneously evaluate for bowel infarction and extent.

The rarity of pediatric MVT impairs the development of evidence-based treatment guidelines. In general, management includes exploratory laparotomy with resection of necrotic bowel followed by post-operative anticoagulation. Multiple adult studies have demonstrated that anticoagulation is effective in recanalization of acute MVT and in preventing thrombus progression and recurrence (63-65). Thus, consensus guidelines endorse early anticoagulation for acute MVT in adults; but do not specify duration of therapy (66). In children, we suggest 3 months of anticoagulation for clearly provoked clots, and 6-12 months of therapy for unprovoked clots (or if the initial risk factor is unresolved). There are insufficient data to support thrombolytic therapy for pediatric MVT.

\section{BUDD-CHIARI SYNDROME (BCS) (HEPATIC VEIN THROMBOSIS)}

Budd-Chiari syndrome is most commonly diagnosed in adults and results from hepatic venous outflow tract obstruction (50, 67). In adults, the obstruction may occur secondary to extrinsic compression of the hepatic veins or hepatic segment of the IVC (segment 5; Figure 1), most commonly by the mass effect of hepatocellular carcinoma, whereas primary thrombosis is often secondary to JAK2 mutated myeloproliferative disease ( $~ 50 \%$ of cases) (67). In children, obstruction of the hepatic veins with or without obstruction of IVC segment 5 has been described. The obstruction may occur due to a membrane occluding the vascular lumen, the origins of which are debated $(50,68)$. An autopsy study of the histopathology of this lesion in adults suggests that the membrane is composed of a fibrous laminar structure derived from organized subacute and chronic thrombi, suggesting thrombotic disease as the underlying etiology (69). This impression is consistent with observations that severe thrombophilias (e.g., antithrombin deficiency, protein C deficiency, JAK2 mutations) are more common than expected in both adult and pediatric series (Table 1) $(50,51,70)$. In the case of membranous obstruction, thrombosis is thought to evolve from venostasis; whereas in the case of primary IVC thrombosis, hepatic vein thrombosis may arise secondary to direct extension of thrombus into the intrahepatic vessels. Other causes of hepatic venous obstruction, including sinusoidal obstruction syndrome, should be excluded. BCS is uniformly fatal without treatment (67).

In both pediatric and adult BCS, there is a male predominance, which in pediatrics is $\sim 1.8$ male:female (51). Most cases present with subacute or chronic symptoms that include insidious onset of abdominal distention (ascites), abdominal wall collateral veins, and portal hypertension $(50,51,68)$. Less common symptoms include GI bleeding, lower extremity edema, jaundice, hepatosplenomegaly, or liver failure (in the acute or fulminant form of the disease) $(50,51,68)$. Pediatric BCS has been reported as a complication of liver transplantation, ventriculoatrial shunt placement, and major abdominal surgery as well as medical conditions such as nephrotic syndrome (NS), ulcerative colitis, and liver abscess (50, 71-75).

Doppler ultrasonography has a diagnostic sensitivity of over $85 \%$ and is considered to be the frontline imaging modality for $\operatorname{BCS}(76,77)$. CT and MRI scans are usually reserved for inconclusive cases. Rarely, when a diagnosis cannot be established by non-invasive imaging modalities, the patient may need venography and/or liver biopsy (78). There are no well-designed trials of anticoagulant therapy (without procedural intervention) for BCS in adults or children $(50,67)$. In adults, there is retrospective data suggesting a beneficial effect, but this is likely restricted to patients with less severe disease $(67,79,80)$. Meanwhile, in children, the anecdotal experience has been disappointing (50). Interventional modalities are thus favored, with several pediatric series reporting promising results $(50,51,81,82)$. Potential interventions include balloon venoplasty, stent placement, mesocaval shunt, portocaval shunt, pericardial patch reconstruction, and transjugular intrahepatic portosystemic shunt (TIPS). The favored approach is dependent upon the extent of pathology; with venoplasty/stent placement favored for patients with short-segment obstructions whereas TIPS is favored in those with long-segment obstructions (51). Regardless of the approach, long-term anticoagulant or antiplatelet therapy is indicated post-procedure to maintain patency. For patients presenting with fulminant hepatic failure or failing intervention, liver transplantation may be lifesaving. Although there are no outcomes data from well-designed pediatric trials of these interventions, in adults their use has resulted in improved survival to $80 \%$ at 5 years (67). 


\section{RENAL VEIN THROMBOSIS (RVT)}

Renal vein thrombosis (Figure 1) is principally a neonatal disease accounting for $15-20 \%$ of neonatal VTE $(46,83,84)$. The incidence of neonatal RVT is $\sim 2.2 / 100,000$ live births, and $0.5 / 1,000$ NICU admissions $(84,85)$. Low renal perfusion pressure, natural anticoagulant deficiency, and renal venous anatomy predispose the neonatal kidney to thrombosis (86). Neonatal RVT originates in the arcuate and interlobular veins with subsequent extension to involve the main renal veins and/or IVC (87). Maternal risk factors for neonatal RVT include diabetes, hypertension, and polyhydramnios; whereas patient risk factors include perinatal asphyxia, hypotension, sepsis, congenital heart disease, and thrombophilia. Neonatal RVT is the most common non-catheter associated VTE in neonates, though UVCs are reported in $15-17 \%$ of cases $(46,48)$.

In older children, RVT has been associated with NS and renal transplantation. The incidence of VTE in adult NS is $\sim 27 \%$ with RVT developing in 31\%; the highest incidence of RVT (37\%) occurring in those with membranous nephropathy (88). In contrast, VTE occurs in only (3\%) of childhood-NS cases of which (10\%) are RVT, possibly because membranous nephropathy is rare in children $(88,89)$. It is thought that NS creates an imbalance between urinary loss and synthetic compensation of hemostasis-related proteins (88). In pediatric renal transplantation, RVT has emerged as a leading cause of graft failure (21\%) (90). Young recipient age, previous transplant, and pre-transplant peritoneal dialysis are predisposing risk factors.

Most cases of neonatal RVT (67\%) are diagnosed within the first 3 days of life $(46,49,91)$. Cardinal signs include macroscopic hematuria, thrombocytopenia, and palpable abdominal mass, though the complete triad is seen in only $13-22 \%$ of cases (49, $91,92)$. Over $50 \%$ of cases are associated with varying degrees of renal dysfunction (48). Neonatal RVT is more common in males (67\%) and most often unilateral (70\%) [left predominant (64\%)] (91). IVC extension occurs in 44 and 15\% have ipsilateral adrenal hemorrhage.

Neonatal RVT diagnosis requires a high index of suspicion and appropriate imaging. Doppler ultrasonography is the modality of choice and progression of imaging findings have been described $(86,93)$. Initially, the affected kidney is enlarged with loss of cortico-medullary differentiation and perivascular echogenic streaking thought to be representative of thrombus within the arcuate and interlobular veins. Subsequently, thrombosis may be seen in the renal vein and IVC. Eventually, a significant proportion of kidneys become atrophic. Initial kidney dimensions may be predictive of outcome (49). Each $1 \mathrm{~mm}$ increase in kidney length predicts a $3 \mathrm{~mL} / \mathrm{min} / 1.73 \mathrm{~m}^{2}$ loss in glomerular filtration rate; such that kidneys $>6 \mathrm{~cm}$ at presentation are rarely salvageable.

Multiple studies have noted a high prevalence of thrombophilic traits (43-68\%) in neonates with RVT, particularly FV Leiden (Table 1) (9, 46-49). Neonatal RVT is associated with significant morbidity (91). At 3.7 years, 71\% develop renal atrophy, 19\% develop hypertension, and 3\% require renal replacement therapy. The role of anticoagulation in preventing these complications remains unclear (92). In a study of 23 neonates with RVT, 33\% of those receiving heparin developed renal atrophy, compared with $100 \%$ in those receiving no anticoagulation. However, subsequent studies revealed no anticoagulation-dependent difference in outcome $(85,91)$. Current consensus guideline recommendations are: (a) supportive care with serial imaging vs. 6-12 weeks anticoagulation for unilateral RVT with no renal dysfunction and no IVC extension, (b) 6-12 weeks anticoagulation for unilateral RVT with extension into the IVC, and (c) thrombolysis followed by anticoagulation vs. anticoagulation alone for bilateral RVT with evidence of renal dysfunction (23). An expert panel has proposed an RVT risk assessment scale and recommends that the patients be reevaluated biannually for $\geq 5$ years to assess renal function (38).

\section{CONCLUSION}

Intra-abdominal VTE is infrequent in children. When present, however, they are associated with significant morbidity. The incidence of thrombophilia may be high, thus the risks and benefits of thrombophilia testing should be carefully considered with the patient and family. The approach to therapy is guided by the involved veins and may include thrombolysis, surgery, and/ or anticoagulation and warrants a multi-disciplinary approach involving pediatric hematology, interventional radiology, and relevant sub-specialties.

\section{AUTHOR CONTRIBUTIONS}

Both authors reviewed the literature, wrote, and edited the manuscript. RK wrote the first draft of the Portal, Mesenteric, and Renal Vein sections. BK wrote the first draft of the IVC and Budd-Chiari sections.

\section{ACKNOWLEDGMENTS}

The authors thank Ms. Lisa Feurer for graphic design (Figure 1). Hemostasis and Thrombosis Research Society which is supported by an educational grant from Bioverativ Therapeutics.

\section{FUNDING}

BK is supported by grant K08DK103982 and L40DK103299 from the National Institutes of Health National Institute of Diabetes and Digestive and Kidney Diseases. RK is supported by a Mentored Research Award (MRA) Hemostasis and Thrombosis Research Society which is supported by an educational grant from Bioverativ Therapeutics. 


\section{REFERENCES}

1. Setty BA, O'Brien SH, Kerlin BA. Pediatric venous thromboembolism in the United States: a tertiary care complication of chronic diseases. Pediatr Blood Cancer (2012) 59(2):258-64. doi:10.1002/pbc.23388

2. Landi D, Beckman MG, Shah NR, Bockenstedt P, Grant AM, Heit JA, et al. Characteristics of abdominal vein thrombosis in children and adults. Thromb Haemost (2013) 109(4):625-32. doi:10.1160/TH12-08-0568

3. Malec L, Young G. Treatment of venous thromboembolism in pediatric patients. Front Pediatr (2017) 5:26. doi:10.3389/fped.2017.00026

4. Shefler A, Gillis J, Lam A, O’Connell AJ, Schell D, Lammi A. Inferior vena cava thrombosis as a complication of femoral vein catheterisation. Arch Dis Child (1995) 72(4):343-5. doi:10.1136/adc.72.4.343

5. van Ommen $\mathrm{CH}$, Heijboer $\mathrm{H}$, Buller $\mathrm{HR}$, Hirasing RA, Heijmans HS, Peters M. Venous thromboembolism in childhood: a prospective two-year registry in The Netherlands. J Pediatr (2001) 139(5):676-81. doi:10.1067/ mpd.2001.118192

6. Massicotte MP, Dix D, Monagle P, Adams M, Andrew M. Central venous catheter related thrombosis in children: analysis of the Canadian Registry of Venous Thromboembolic Complications. J Pediatr (1998) 133(6):770-6. doi:10.1016/S0022-3476(98)70149-0

7. Male C, Julian JA, Massicotte P, Gent M, Mitchell L. Significant association with location of central venous line placement and risk of venous thrombosis in children. Thromb Haemost (2005) 94(3):516-21. doi:10.1160/TH0302-0091

8. Koc Z, Oguzkurt L. Interruption or congenital stenosis of the inferior vena cava: prevalence, imaging, and clinical findings. Eur J Radiol (2007) 62(2):257-66. doi:10.1016/j.ejrad.2006.11.028

9. Heller C, Schobess R, Kurnik K, Junker R, Gunther G, Kreuz W, et al. Abdominal venous thrombosis in neonates and infants: role of prothrombotic risk factors-a multicentre case-control study. For the Childhood ThrombophiliaStudy Group. BrJ Haematol (2000) 111(2):534-9. doi:10.1111/j. 1365-2141.2000.02349.x

10. Schullinger JN, Santulli TV, Berdon WE, Wigger HJ, MacMillan RW, Demartini PD, et al. Calcific thrombi of the inferior vena cava in infants and children. J Pediatr Surg (1978) 13(4):429-34. doi:10.1016/S0022-3468(78) 80471-0

11. Kassner EG, Baumstark A, Kinkhabwala MN, Ablow RC, Haller JO. Calcified thrombus in the inferior vena cava in infants and children. Pediatr Radiol (1976) 4(3):167-71. doi:10.1007/BF00975351

12. Halparin J, Monagle P, Newall F. Congenital abnormalities of the inferior vena cava presenting clinically in adolescent males. Thromb Res (2015) 135(4):648-51. doi:10.1016/j.thromres.2015.01.032

13. Parma M, Belotti D, Marinoni S, Pogliani EM. Congenital absence of the inferior vena cava and genetic coagulation abnormalities: a rare associated risk factor for recurrent idiopathic deep vein thrombosis. Clin Appl Thromb Hemost (2003) 9(4):347-8. doi:10.1177/107602960300900412

14. Ruggeri M, Tosetto A, Castaman G, Rodeghiero F. Congenital absence of the inferior vena cava: a rare risk factor for idiopathic deep-vein thrombosis. Lancet (2001) 357(9254):441. doi:10.1016/S0140-6736(00) 04010-1

15. Kraft C, Schuettfort G, Weil Y, Tirneci V, Kasper A, Haberichter B, et al. Thrombosis of the inferior vena cava and malignant disease. Thromb Res (2014) 134(3):668-73. doi:10.1016/j.thromres.2014.07.012

16. Linnemann B, Schmidt $H$, Schindewolf $M$, Erbe $M$, Zgouras D, Grossmann R, et al. Etiology and VTE risk factor distribution in patients with inferior vena cava thrombosis. Thromb Res (2008) 123(1):72-8. doi:10.1016/j. thromres.2008.01.004

17. Lambert M, Marboeuf P, Midulla M, Trillot N, Beregi JP, MounierVehier C, et al. Inferior vena cava agenesis and deep vein thrombosis: 10 patients and review of the literature. Vasc Med (2010) 15(6):451-9. doi:10.1177/ 1358863 X10391355

18. Goodpasture ML, Zeller KA, Petty JK. Pediatric child abuse victim with posttraumatic inferior vena cava thrombosis. Pediatr Surg Int (2014) 30(5):569-71. doi:10.1007/s00383-014-3487-9

19. Siddiqui M, Gupta A, Kazmi A, Chandra D, Grover V, Gupta V. Inferior vena caval and right atrial thrombus complicating amoebic liver abscess. Interact Cardiovasc Thorac Surg (2013) 17(5):872-4. doi:10.1093/icvts/ ivt350
20. Bagri N, Yadav D, Hemal A. Inferior vena caval and right atrial thrombosis: complicating pyogenic liver abscess. Indian Pediatr (2013) 50(7):701-3. doi:10.1007/s13312-013-0177-y

21. Carlton GR, Towne BH, Bryan RW, Chang JH. Obstruction of the suprahepatic inferior vena cava as a complication of giant omphalocele repair. J Pediatr Surg (1979) 14(6):733-4. doi:10.1016/S0022-3468(79)80255-9

22. Smillie RP, Shetty M, Boyer AC, Madrazo B, Jafri SZ. Imaging evaluation of the inferior vena cava. Radiographics (2015) 35(2):578-92. doi:10.1148/ rg.352140136

23. Monagle P, Chan AK, Goldenberg NA, Ichord RN, Journeycake JM, NowakGottl U, et al. Antithrombotic therapy in neonates and children: antithrombotic therapy and prevention of thrombosis, 9th ed: American College of Chest physicians evidence-based clinical practice guidelines. Chest (2012) 141(2 Suppl):737S-801S. doi:10.1378/chest.11-2308

24. Hausler M, Hubner D, Delhaas T, Muhler EG. Long term complications of inferior vena cava thrombosis. Arch Dis Child (2001) 85(3):228-33. doi:10.1136/adc.85.3.228

25. Manco-Johnson MJ. How I treat venous thrombosis in children. Blood (2006) 107(1):21-9. doi:10.1182/blood-2004-11-4211

26. Vedantham S, Piazza G, Sista AK, Goldenberg NA. Guidance for the use of thrombolytic therapy for the treatment of venous thromboembolism. J Thromb Thrombolysis (2016) 41(1):68-80. doi:10.1007/s11239-0151318-Z

27. Goel R, Vedantham S, Goldenberg NA. Antithrombotic therapies: anticoagulation and thrombolysis. Pediatr Clin North Am (2013) 60(6):1463-74. doi:10.1016/j.pcl.2013.09.005

28. Frazer JR, Ing FF. Stenting of stenotic or occluded iliofemoral veins, superior and inferior vena cavae in children with congenital heart disease: acute results and intermediate follow up. Catheter Cardiovasc Interv (2009) 73(2):181-8. doi: $10.1002 / \mathrm{ccd} .21790$

29. Sagban TA, Grotemeyer D, Balzer KM, Tekath B, Pillny M, Grabitz K, et al. Surgical treatment for agenesis of the vena cava: a single-centre experience in 15 cases. Eur J Vasc Endovasc Surg (2010) 40(2):241-5. doi:10.1016/j. ejvs.2010.04.009

30. Morag I, Epelman M, Daneman A, Moineddin R, Parvez B, Shechter T, et al. Portal vein thrombosis in the neonate: risk factors, course, and outcome. J Pediatr (2006) 148(6):735-9. doi:10.1016/j.jpeds.2006.01.051

31. Alvarez F, Bernard O, Brunelle F, Hadchouel P, Odievre M, Alagille D. Portal obstruction in children. I. Clinical investigation and hemorrhage risk. J Pediatr (1983) 103(5):696-702. doi:10.1016/S0022-3476(83)80460-0

32. Ferri PM, Ferreira AR, Fagundes ED, Liu SM, Roquete ML, Penna FJ. Portal vein thrombosis in children and adolescents: 20 years experience of a pediatric hepatology reference center. Arq Gastroenterol (2012) 49(1):69-76. doi:10.1590/S0004-28032012000100012

33. Gharehbaghi MM, Nemati M, Hosseinpour SS, Taei R, Ghargharechi R. Umbilical vascular catheter associated portal vein thrombosis detected by ultrasound. Indian J Pediatr (2011) 78(2):161-4. doi:10.1007/s12098-0100223-x

34. Guimaraes H, Castelo L, Guimaraes J, Cardoso A, d'Orey C, Mateus M, et al. Does umbilical vein catheterization to exchange transfusion lead to portal vein thrombosis? Eur J Pediatr (1998) 157(6):461-3. doi:10.1007/s004310 050853

35. Kim JH, Lee YS, Kim SH, Lee SK, Lim MK, Kim HS. Does umbilical vein catheterization lead to portal venous thrombosis? Prospective US evaluation in 100 neonates. Radiology (2001) 219(3):645-50. doi:10.1148/ radiology.219.3.r01jn17645

36. Sakha SH, Rafeey M, Tarzamani MK. Portal venous thrombosis after umbilical vein catheterization. Indian J Gastroenterol (2007) 26(6):283-4.

37. Schwartz DS, Gettner PA, Konstantino MM, Bartley CL, Keller MS, Ehrenkranz RA, et al. Umbilical venous catheterization and the risk of portal vein thrombosis. JPediatr (1997) 131(5):760-2. doi:10.1016/ S0022-3476(97)70109-4

38. Rajpurkar M, Sharathkumar A, Williams S, Lau K, Ling SC, Chan AK. Recommendations for the assessment of non-extremity venous thromboembolism outcomes: communication from the SSC of the ISTH. J Thromb Haemost (2015) 13(3):477-80. doi:10.1111/jth.12809

39. Morag I, Shah PS, Epelman M, Daneman A, Strauss T, Moore AM. Childhood outcomes of neonates diagnosed with portal vein thrombosis. J Paediatr Child Health (2011) 47(6):356-60. doi:10.1111/j.1440-1754.2010.01987.x 
40. Cohen J, Edelman RR, Chopra S. Portal vein thrombosis: a review. Am J Med (1992) 92(2):173-82. doi:10.1016/0002-9343(92)90109-O

41. El-Karaksy HM, El-Koofy N, Mohsen N, Helmy H, Nabil N, El-Shabrawi M. Extrahepatic portal vein obstruction in Egyptian children. JPediatr Gastroenterol Nutr (2015) 60(1):105-9. doi:10.1097/MPG.0000000000000548

42. Ferri PM, Rodrigues Ferreira A, Fagundes ED, Xavier SG, Dias Ribeiro D, Fernandes AP, et al. Evaluation of the presence of hereditary and acquired thrombophilias in Brazilian children and adolescents with diagnoses of portal vein thrombosis. J Pediatr Gastroenterol Nutr (2012) 55(5):599-604. doi:10.1097/MPG.0b013e318261814d

43. Pietrobattista A, Luciani M, Abraldes JG, Candusso M, Pancotti S, Soldati M, et al. Extrahepatic portal vein thrombosis in children and adolescents: influence of genetic thrombophilic disorders. World J Gastroenterol (2010) 16(48):6123-7. doi:10.3748/wjg.v16.i48.6123

44. Primignani M. Portal vein thrombosis, revisited. Dig Liver Dis (2010) 42(3):163-70. doi:10.1016/j.dld.2009.08.003

45. Primignani M, Barosi G, Bergamaschi G, Gianelli U, Fabris F, Reati R, et al. Role of the JAK2 mutation in the diagnosis of chronic myeloproliferative disorders in splanchnic vein thrombosis. Hepatology (2006) 44(6):1528-34. doi:10.1002/hep.21435

46. Kuhle S, Massicotte P, Chan A, Mitchell L. A case series of 72 neonates with renal vein thrombosis. Data from the 1-800-NO-CLOTS Registry. Thromb Haemost (2004) 92(4):729-33. doi:10.1160/TH04-02-0131

47. Kosch A, Kuwertz-Broking E, Heller C, Kurnik K, Schobess R, NowakGottl U. Renal venous thrombosis in neonates: prothrombotic risk factors and long-term follow-up. Blood (2004) 104(5):1356-60. doi:10.1182/ blood-2004-01-0229

48. Marks SD, Massicotte MP, Steele BT, Matsell DG, Filler G, Shah PS, et al. Neonatal renal venous thrombosis: clinical outcomes and prevalence of prothrombotic disorders. JPediatr (2005) 146(6):811-6. doi:10.1016/j. jpeds.2005.02.022

49. Winyard PJ, Bharucha T, De Bruyn R, Dillon MJ, van't Hoff W, Trompeter RS, et al. Perinatal renal venous thrombosis: presenting renal length predicts outcome. Arch Dis Child Fetal Neonatal Ed (2006) 91(4):F273-8. doi:10.1136/adc.2005.083717

50. Nagral A, Hasija RP, Marar S, Nabi F. Budd-Chiari syndrome in children: experience with therapeutic radiological intervention. J Pediatr Gastroenterol Nutr (2010) 50(1):74-8. doi:10.1097/MPG.0b013e3181aecb63

51. Kathuria R, Srivastava A, Yachha SK, Poddar U, Baijal SS. Budd-Chiari syndrome in children: clinical features, percutaneous radiological intervention, and outcome. Eur J Gastroenterol Hepatol (2014) 26(9):1030-8. doi:10.1097/ MEG.0000000000000144

52. Ling SC. Advances in the evaluation and management of children with portal hypertension. Semin Liver Dis (2012) 32(4):288-97. doi:10.1055/ s-0032-1329897

53. Lautz TB, Sundaram SS, Whitington PF, Keys L, Superina RA. Growth impairment in children with extrahepatic portal vein obstruction is improved by mesenterico-left portal vein bypass. J Pediatr Surg (2009) 44(11):2067-70. doi:10.1016/j.jpedsurg.2009.05.016

54. Mack CL, Superina RA, Whitington PF. Surgical restoration of portal flow corrects procoagulant and anticoagulant deficiencies associated with extrahepatic portal vein thrombosis. J Pediatr (2003) 142(2):197-9. doi:10.1067/ mpd.2003.93

55. Mack CL, Zelko FA, Lokar J, Superina R, Alonso EM, Blei AT, et al. Surgically restoring portal blood flow to the liver in children with primary extrahepatic portal vein thrombosis improves fluid neurocognitive ability. Pediatrics (2006) 117(3):e405-12. doi:10.1542/peds.2005-1177

56. Shneider BL, de Ville de Goyet J, Leung DH, Srivastava A, Ling SC, Duche $\mathrm{M}$, et al. Primary prophylaxis of variceal bleeding in children and the role of MesoRex bypass: summary of the Baveno VI pediatric satellite symposium. Hepatology (2016) 63(4):1368-80. doi:10.1002/hep. 28153

57. Hayakawa T, Morimoto A, Nozaki Y, Kashii Y, Aihara T, Maeda K, et al. Mesenteric venous thrombosis in a child with type 2 protein $\mathrm{S}$ deficiency. J Pediatr Hematol Oncol (2011) 33(2):141-3. doi:10.1097/ MPH.0b013e3181fce4d4

58. Oguzkurt P, Senocak ME, Ciftci AO, Tanyel FC, Buyukpamukcu N. Mesenteric vascular occlusion resulting in intestinal necrosis in children. J Pediatr Surg (2000) 35(8):1161-4. doi:10.1053/jpsu.2000.8718
59. Pergantou H, Avgeri M, Komitopoulou A, Xafaki P, Kapsimali Z, Mazarakis $\mathrm{M}$, et al. Venous thromboembolism at uncommon sites in neonates and children. J Pediatr Hematol Oncol (2014) 36(8):624-9. doi:10.1097/MPH. 0000000000000116

60. Ulinski T, Guigonis V, Baudet-Bonneville V, Auber F, Garcette K, Bensman A. Mesenteric thrombosis causing short bowel syndrome in nephrotic syndrome. Pediatr Nephrol (2003) 18(12):1295-7. doi:10.1007/s00467-003-1281-3

61. Kumar S, Sarr MG, Kamath PS. Mesenteric venous thrombosis. N Engl J Med (2001) 345(23):1683-8. doi:10.1056/NEJMra010076

62. Boley SJ, Kaleya RN, Brandt LJ. Mesenteric venous thrombosis. Surg Clin North Am (1992) 72(1):183-201. doi:10.1016/S0039-6109(16)45634-3

63. Abdu RA, Zakhour BJ, Dallis DJ. Mesenteric venous thrombosis-1911 to 1984. Surgery (1987) 101(4):383-8.

64. Amitrano L, Guardascione MA, Scaglione M, Pezzullo L, Sangiuliano N, Armellino MF, et al. Prognostic factors in noncirrhotic patients with splanchnic vein thromboses. Am J Gastroenterol (2007) 102(11):2464-70. doi:10.1111/j.1572-0241.2007.01477.x

65. Dentali F, Ageno W, Witt D, Malato A, Clark N, Garcia D, et al. Natural history of mesenteric venous thrombosis in patients treated with vitamin $\mathrm{K}$ antagonists: a multi-centre, retrospective cohort study. Thromb Haemost (2009) 102(3):501-4. doi:10.1160/TH08-12-0842

66. Kearon C, Akl EA, Comerota AJ, Prandoni P, Bounameaux H, Goldhaber SZ, et al. Antithrombotic therapy for VTE disease: antithrombotic therapy and prevention of thrombosis, 9th ed: American College of Chest physicians evidence-based clinical practice guidelines. Chest (2012) 141(2 Suppl):419S-94S. doi:10.1378/chest.11-2301

67. Plessier A, Valla DC. Budd-Chiari syndrome. Semin Liver Dis (2008) 28(3):259-69. doi:10.1055/s-0028-1085094

68. Hoffman HD, Stockland B, von der Heyden U. Membranous obstruction of the inferior vena cava with Budd-Chiari syndrome in children: a report of nine cases. J Pediatr Gastroenterol Nutr (1987) 6(6):878-84. doi:10.1097/ 00005176-198711000-00010

69. Kage M, Arakawa M, Kojiro M, Okuda K. Histopathology of membranous obstruction of the inferior vena cava in the Budd-Chiari syndrome. Gastroenterology (1992) 102(6):2081-90. doi:10.1016/0016-5085(92)90336-W

70. Amarapurkar DN, Punamiya SJ, Patel ND. Changing spectrum of BuddChiari syndrome in India with special reference to non-surgical treatment. World J Gastroenterol (2008) 14(2):278-85. doi:10.3748/wig.14.278

71. Lilova M, Velkovski IG, Velichkov NI. Budd-Chiari syndrome and inferior vena cava thrombosis in a nephrotic child. Pediatr Nephrol (2000) 14(5):412-5. doi:10.1007/s004670050785

72. Kraut J, Berman JH, Gunasekaran TS, Allen R, McFadden J, Messersmith R, et al. Hepatic vein thrombosis (Budd-Chiari syndrome) in an adolescent with ulcerative colitis. J Pediatr Gastroenterol Nutr (1997) 25(4):417-20. doi:10.1097/00005176-199710000-00010

73. O'Shea PA. Inferior vena cava and hepatic vein thrombosis as a rare complication of ventriculoatrial shunt. Case report. J Neurosurg (1978) 48(1):143-5. doi:10.3171/jns.1978.48.1.0143

74. Krishna Kumar G, Sharif K, Mayer D, Mirza D, Foster K, Kelly D, et al. Hepatic venous outflow obstruction in paediatric liver transplantation. Pediatr Surg Int (2010) 26(4):423-5. doi:10.1007/s00383-010-2564-y

75. Kaabachi O, Berg A, Laguenie G, Adamsbaum C, Bargy F, Helardot PG. Budd-Chiari syndrome following repair of a giant omphalocele. Eur J Pediatr Surg (1998) 8(6):371-2. doi:10.1055/s-2008-1071236

76. Bolondi L, Gaiani S, Li Bassi S, Zironi G, Bonino F, Brunetto M, et al. Diagnosis of Budd-Chiari syndrome by pulsed Doppler ultrasound. Gastroenterology (1991) 100(5 Pt 1):1324-31. doi:10.1016/0016-5085(91)90785-J

77. Chawla Y, Kumar S, Dhiman RK, Suri S, Dilawari JB. Duplex Doppler sonography in patients with Budd-Chiari syndrome. J Gastroenterol Hepatol (1999) 14(9):904-7. doi:10.1046/j.1440-1746.1999.01969.x

78. Liu L, Qi XS, Zhao Y, Chen H, Meng XC, Han GH. Budd-Chiari syndrome: current perspectives and controversies. Eur Rev Med Pharmacol Sci (2016) 20(15):3273-81.

79. Zeitoun G, Escolano S, Hadengue A, Azar N, El Younsi M, Mallet A, et al. Outcome of Budd-Chiari syndrome: a multivariate analysis of factors related to survival including surgical portosystemic shunting. Hepatology (1999) 30(1):84-9. doi:10.1002/hep.510300125

80. Darwish Murad S, Valla DC, de Groen PC, Zeitoun G, Hopmans JA, Haagsma EB, et al. Determinants of survival and the effect of portosystemic 
shunting in patients with Budd-Chiari syndrome. Hepatology (2004) 39(2):500-8. doi:10.1002/hep.20064

81. Gentil-Kocher S, Bernard O, Brunelle F, Hadchouel M, Maillard JN, Valayer J, et al. Budd-Chiari syndrome in children: report of 22 cases. J Pediatr (1988) 113(1 Pt 1):30-8. doi:10.1016/S0022-3476(88)80524-9

82. Odell JA, Rode H, Millar AJ, Hoffman HD. Surgical repair in children with the Budd-Chiari syndrome. J Thorac Cardiovasc Surg (1995) 110(4 Pt 1):916-23. doi:10.1016/S0022-5223(05)80158-8

83. Nowak-Gottl U, von Kries R, Gobel U. Neonatal symptomatic thromboembolism in Germany: two year survey. Arch Dis Child Fetal Neonatal Ed (1997) 76(3):F163-7. doi:10.1136/fn.76.3.F163

84. Schmidt B, Andrew M. Neonatal thrombosis: report of a prospective Canadian and international registry. Pediatrics (1995) 96(5 Pt 1):939-43.

85. Bokenkamp A, von Kries R, Nowak-Gottl U, Gobel U, Hoyer PF. Neonatal renal venous thrombosis in Germany between 1992 and 1994: epidemiology, treatment and outcome. Eur J Pediatr (2000) 159(1-2):44-8. doi:10.1007/ s004310050008

86. Brandao LR, Simpson EA, Lau KK. Neonatal renal vein thrombosis. Semin Fetal Neonatal Med (2011) 16(6):323-8. doi:10.1016/j.siny.2011. 08.004

87. Arneil GC, MacDonald AM, Sweet EM. Renal venous thrombosis. Clin Nephrol (1973) 1(3):119-31.

88. Kerlin BA, Ayoob R, Smoyer WE. Epidemiology and pathophysiology of nephrotic syndrome-associated thromboembolic disease. Clin JAm Soc Nephrol (2012) 7(3):513-20. doi:10.2215/CJN.10131011

89. Kerlin BA, Blatt NB, Fuh B, Zhao S, Lehman A, Blanchong C, et al. Epidemiology and risk factors for thromboembolic complications of childhood nephrotic syndrome: a Midwest Pediatric Nephrology Consortium
(MWPNC) study. J Pediatr (2009) 155(1):105-10,10.e1. doi:10.1016/j.jpeds. 2009.01.070

90. McDonald RA, Smith JM, Stablein D, Harmon WE. Pretransplant peritoneal dialysis and graft thrombosis following pediatric kidney transplantation: a NAPRTCS report. Pediatr Transplant (2003) 7(3):204-8. doi:10.1034/j.1399-3046.2003.00075.x

91. Lau KK, Stoffman JM, Williams S, McCusker P, Brandao L, Patel S, et al. Neonatal renal vein thrombosis: review of the English-language literature between 1992 and 2006. Pediatrics (2007) 120(5):e1278-84. doi:10.1542/ peds.2007-0510

92. Zigman A, Yazbeck S, Emil S, Nguyen L. Renal vein thrombosis: a 10-year review. J Pediatr Surg (2000) 35(11):1540-2. doi:10.1053/jpsu.2000.18302

93. Cremin BJ, Davey H, Oleszczuk-Raszke K. Neonatal renal venous thrombosis sequential ultrasonic appearances. Clin Radiol (1991) 44(1):52-5. doi:10.1016/ S0009-9260(05)80228-4

Conflict of Interest Statement: BK has received research support from the CSL Behring Foundation, NovoNordisk A/S, and Bayer Healthcare US and also serves on advisory boards for NovoNordisk A/S and Bayer Healthcare US. RK serves on an advisory board for Bayer Healthcare US. The authors have no actual or potential conflict of interest.

Copyright $\odot 2017$ Kumar and Kerlin. This is an open-access article distributed under the terms of the Creative Commons Attribution License (CC BY). The use, distribution or reproduction in other forums is permitted, provided the original author(s) or licensor are credited and that the original publication in this journal is cited, in accordance with accepted academic practice. No use, distribution or reproduction is permitted which does not comply with these terms. 